\title{
Antioxidative efficiency of an anthocyanin rich bilberry extract in the human colon tumor cell lines Caco-2 and HT-29
}

\author{
Markus Schantz, Christiane Mohn, Matthias Baum and Elke Richling* \\ Food Chemistry and Toxicology, Molecular Nutrition, University of Kaiserslautern, Kaiserslautern, Germany
}

\begin{abstract}
Bilberries (Vaccinium myrtillus L.) and its major polyphenolic constituents, the anthocyanins, are discussed to be preventive against diseases, such as colon cancer or inflammatory bowel diseases (e.g. Crohn's disease, ulcerative colitis), are associated with oxidative stress. Therefore the gastrointestinal tract (GIT) might be a target for prevention of these diseases. In this study antioxidative efficiency of a commercially available anthocyanin rich bilberry extract (BE) was investigated in vitro in the human colon tumor cell lines Caco-2 and HT-29. The cell cytotoxicity of the BE was measured by alamar blue assay. Modulation of intracellular generated reactive oxygen species (ROS) levels was investigated by dichlorfluorescein assay (DCF). Oxidative DNA damage was monitored by single-cell gel electrophoresis (comet assay) with additional treatment of the DNA with formamido-pyrimidinglycosylase (FPG) to enhance sensitivity towards ROS induced DNA lesions. Modulation of the total glutathione (tGSH) level was assayed in a photometric kinetic assay. In a two step protocol cells were first treated with the protective extract $(5-500 \mu \mathrm{g} / \mathrm{ml} ; 1$ and $24 \mathrm{~h}$ ) and then with the redox-cycler menadione (Md) (HT-29: $20 \mu \mathrm{M}$ and Caco-2: $6 \mu \mathrm{M}$ ) or the oxidant TBH (tert-butyl hydroperoxide) $(250 \mu \mathrm{M}, 40 \mathrm{~min})$. Under all conditions tested BE was not cytotoxic in Caco-2 and HT-29 cells. The data achieved revealed that BE significantly reduce ROS level in HT-29 $(250 \mu \mathrm{g} / \mathrm{ml} ; 24 \mathrm{~h}, p<0.05)$ and Caco-2 $(50 \mu \mathrm{g} / \mathrm{ml} ; 1 \mathrm{~h}, p<0.05)$ cells. Significant decrease of induced DNA damage was detected in Caco-2 cells after BE treatment $(5 \mu \mathrm{g} / \mathrm{ml} ; 24 \mathrm{~h}$; FPG, $p<0.05)$. Trend towards increase of tGSH was observed at concentrations of $50-500 \mu \mathrm{g} / \mathrm{ml} \mathrm{BE} \mathrm{in} \mathrm{Caco-2}$ cells after $24 \mathrm{~h}$ incubation.

In total, the BE was shown to possess antioxidative activity under the used assay conditions towards prevention of oxidative DNA damage, reduction of intracellular ROS and cellular tGSH.
\end{abstract}

Keywords: Anthocyanins, bilberries, antioxidants, DNA damage, glutathione, ROS, cytotoxicity

\section{Introduction}

Anthocyanins (ACN) and their glycosides are polyphenols that play an important role in fruits, flowers and vegetables and are responsible for their bright colours like orange, blue and red, which help to attract animals $[11,27,48]$ and prevent plants from oxidative stress due to their photoprotective functions such as light induced photooxidation or against UVB damage [7]. Polyphenols showed beneficial effects on degenerative diseases and are regarded to exhibit protective effects against cardiovascular diseases and cancer [33]. The main daily intake of anthocyanins averages $12.7 \mathrm{mg} /$ person in USA and $82 \mathrm{mg} /$ person in Finland [45]. Among dietary sources of anthocyanins, bilberry (vaccinium myrtillus L.) is one of the richest [23, 29], with varying anthocyanin patterns [34]. In contrast to other flavonoids, anthocyanidins consist of a flavylium ion whereas the structural variations are due

*Corresponding author: Prof. Dr. Elke Richling, Food Chemistry and Toxicology, Molecular Nutrition, University of Kaiserslautern, ErwinSchroedinger-Str. 52, 67663 Kaiserslautern, Germany. Tel.: +49 631205 4061; Fax: +49 631205 3085; E-mail: richling@ chemie.uni-kl.de. 
to differences in the number of hydroxyl and methoxyl groups at the B-ring. To the anthocyanidin aglycons sugar moieties (like glucose, galactose, arabinose, rhamnose and xylose $[8,12]$ ) are attached to the phenolic molecule at position 3 and 7 ; and less frequently to $3^{\prime}$ and $5^{\prime}$ positions $[11,26]$. Structures of the ACN found in bilberries are shown in Fig. 1.

During the last decades, there has been intense interest in beneficial health effects of anthocyanins because of increasing evidence demonstrating potential biological effects after consumption of fruits and vegetables [3, 41]. A number of studies in vitro and in vivo have been reported that anthocyanins from bilberries are strong antioxidants $[17,38,43]$, inhibit the growth of a range of tumor cells [16, 24, 31], induce apoptosis [14, 19] and have anticarcinogenic $[6,10]$ properties.

Diseases of the gastrointestinal tract like inflammatory bowel diseases (crohn's disease, ulcerative colitis) or colon cancer, are associated with an imbalance in the cellular redox system based on an increased level of reactive oxygen species (ROS) [36]. The antioxidant potential of flavonoids and other polyphenols is their ability to scavenge ROS and protect the organism against oxidative stress induced damage [41].

The specific object of this study was to investigate the in vitro antioxidant effectiveness of a BE. In vitro human adenocarcinoma cell lines HT-29 and Caco-2, representing characteristics of adult colon cells. As markers for antioxidant capacity the intracellular ROS level (DCF assay), oxidative DNA damage (comet assay), cellular tGSH level (kinetic assay) and cytotoxicity (alamar blue assay) was used.

\section{Materials and methods}

\subsection{Chemicals, cells and media}

All chemicals and solvents were of analytical grade or complied with the standards needed for cell culture experiments. The BE was provided from Kaden Biochemicals (Hamburg, Germany) (BE, 600761 Bilberry Extract; consisted of 25\% anthocyanins), formamido-pyrimidinglycosylase (FPG) was a gift of Prof. A.R. Collins (University Oslo, Norway), HT-29 and Caco-2 cells were obtained from DSMZ (Braunschweig, Germany), resazurin, tertbutyl hydroperoxide (TBH), menadione (Md), reduced/oxidized glutathione, glutathione reductase (GSR), catalase, potassium persulfate, 5,5'-dithiobis(2-nitrobenzoic acid) (DTNB), 5-sulfosalicylic acid (SSA), dimethylsulfoxide (DMSO) and ethidium bromide were purchased from Sigma Aldrich (Munich, Germany). NADPH and 2',7'dichlorfluorescein diacetat (DCFH-DA) were purchased from Fluka (Deisenhofen, Germany), low and normal melting agarose from Bio-Rad (Munich, Germany), bicinchoninic acid (BCA) protein quantification kit was from Interchim (Sankt Augustin-Buisdorf, Germany). Cell culture media (DMEM and DMEM/F-12 (1:1)) and reagents (fetal calf serum (FCS), penicillin/streptomycin, Trypsin $0.05 \%$ ) were purchased from Invitrogen (Karlsruhe, Germany). Cell culture material (Petri dishes, well plates, flasks, etc.) were from Greiner Bio-One (Essen, Germany).

\subsection{Bilberry extract $(B E)$}

The BE was made from European bilberry pomace (Vaccinium myrtillus L.) by extraction with methanol, filtration, evaporation and lyophilisation. It was stored dry and cold at $-24^{\circ} \mathrm{C}$. The anthocyanin content was adjusted at $25 \%$.

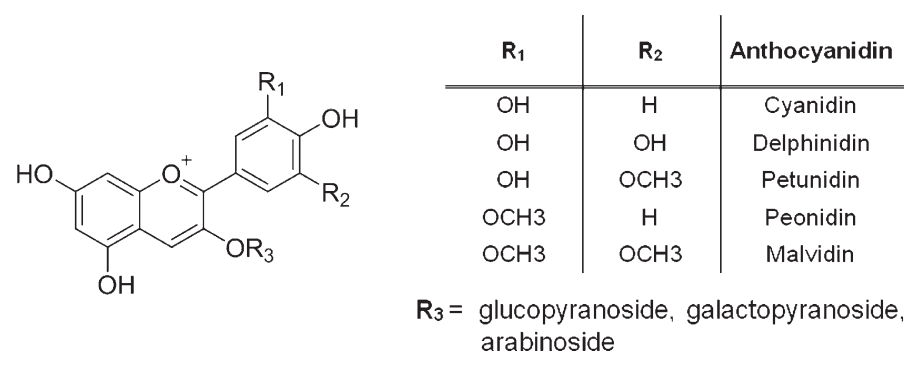

Fig. 1. Chemical structure of the most common anthocyanins found in bilberry. 
The BE also contains other polyphenols, tannins, carbohydrates and roughages. Basic characterisation of the anthocyanin profile was performed by Symrise GmbH \& Co.KG. Control measurements of BE were performed by using a Jasco HPLC-UV system equipped with Jasco PU-2080 intelligent HPLC pump, Jasco LG-2080-02 ternary gradient unit, Jasco UV-2075 plus intelligent UV/VIS detector, Jasco DG-2080-53 3-line-degaser, AS-2055 plus intelligent sampler (Jasco, Gross-Umstadt, Germany). Separation of 15 anthocyanins was performed on a phenomenex Luna C18 (2) column (Phenomenex, Aschaffenburg, Germany) equipped with a security guard column; injection volume: $20 \mu \mathrm{l}$; flow rate: $0.5 \mathrm{ml} / \mathrm{min}$; solvent A (acetonitrile/water/HCOOH; 87/3/10 v/v/v); solvent B (acetonitrile/water/HCOOH; $50 / 40 / 10 \mathrm{v} / \mathrm{v} / \mathrm{v})$; gradient elution: 0-20 min from 2-14\% B, 20-40 m hold 14\% B, 40-50 min to 15\% B, 50-55 min to $19 \% \mathrm{~B}, 55-65 \mathrm{~min}$ to $20 \% \mathrm{~B}, 65-110 \mathrm{~min}$ washing and reequilibration, detection wavelength $520 \mathrm{~nm}$.

\subsection{Cell culture}

HT-29 cells were cultivated in $175 \mathrm{~cm}^{2}$ flasks in DMEM with addition of 10\% FCS, Caco-2 cells in DMEM/F12 (1:1) with addition of $20 \%$ FCS. Both were supplemented with $100 \mathrm{U} / \mathrm{ml}$ penicillin and $100 \mu \mathrm{g} / \mathrm{ml}$ streptomycin in humidified atmosphere with $5 \% \mathrm{CO}_{2}$ at $37^{\circ} \mathrm{C}$.

\subsection{Incubations with $B E$}

HT-29 and Caco- 2 cells were seeded in Petri dishes $(6 \mathrm{~cm}$ for HT-29, $9 \mathrm{~cm}$ for Caco-2; tGSH level and comet assay: for $1 \mathrm{~h}$ incubation $1.5 \times 10^{6}$ cells per dish and for $24 \mathrm{~h}$ incubation $10^{6}$ cells per dish, respectively), cultivated for $24 \mathrm{~h}$ (cultures were semiconfluent and undifferentiated), washed with PBS and incubated in the first step with the BE in incubation medium containing 10\% FCS for Caco-2 and 5\% for HT-29 cells (dissolved in DMSO at a final concentration of 1\%). In the second step, cells were treated with Md (HT-29: $20 \mu \mathrm{M}$ and Caco-2: $6 \mu \mathrm{M})$. After incubation, cells were washed with PBS and isolated by Trypsin $(0.05 \%)$ treatment. Cell suspensions were directly used for tGSH level analysis and comet assay. For DCF assay, cells were seeded in 96 well plates (HT-29: $3.2 \times 10^{4}$ and Caco-2: $2.0 \times 10^{4}$ ) and incubated with BE (dissolved in DMSO at a final concentration of 1\%). The alamar blue assay was used to check for cytotoxicity, therefore cells were seeded in 48 well plates (HT-29: $6.0 \times 10^{4}$ and Caco-2: $5.5 \times 10^{4}$ ) and incubated with BE (dissolved in DMSO at a final concentration of $1 \%$ ). All incubations were performed in the presence of catalase $(100 \mathrm{U} / \mathrm{ml})$ to inhibit formation of extracellular hydrogen peroxide $\left(\mathrm{H}_{2} \mathrm{O}_{2}\right)$, resulting from pro-oxidative interaction of phenolic compounds with cell media constituents like metal ions [13, 22]. Addition of catalase provides an opportunity to preclude effects resulted from extracellular generated $\mathrm{H}_{2} \mathrm{O}_{2}$.

\subsection{Intracellular ROS level (DCF assay)}

DCF assay was performed according to Wang and Joseph [42] with modifications [5]. Briefly, after BE treated cells were incubated for 30 min with DCFH-DA dissolved in DMSO (50 $\mu \mathrm{M}$ in PBS; $\mathrm{pH} 7.0$ ), washed and incubated with TBH (250 $\mu \mathrm{M}$ in PBS; pH 7.4) for another $40 \mathrm{~min}$. After TBH treatment, formation of DCF was measured as increase of fluorescence intensity between 0 and $30 \mathrm{~min}$ in a microplate reader (MWG, Ebersberg, Germany) and stated as relative fluorescence intensity (FI) in percent control (without BE treatment).

\subsection{Cellular GSH level (kinetic assay)}

The cellular GSH level was measured by photometric determination of 5-thio-2-nitrobenzoate (TNB), formed from DTNB [35]. After BE incubation, cells were treated with Md (HT-29: $20 \mu \mathrm{M}$ and Caco-2: $6 \mu \mathrm{M}$ for $1 \mathrm{~h}$ in serum free medium) suspension. The formation of TNB after 2 min reaction time was measured in 96 well plates by microplate reader (MWG, Ebersberg, Germany) at $412 \mathrm{~nm}$. The GSH level was specified as nanomoles per milligram of protein and expressed as percent of Md-treated control.

\subsection{Oxidative DNA damage (comet assay)}

After extract incubation, cells were incubated with Md (see above) and isolated by trypsin treatment. The detailed process of the alkine single cell gel electrophoresis was described previously [35]. Briefly, 70,000 cells per preparation 
were centrifuged $\left(10 \mathrm{~min}, 2000 \mathrm{rpm}, 4^{\circ} \mathrm{C}\right)$ and the pellet was resuspended with low melting agarose, applied on a previously prepared microscope slide (per condition, 2 slides with and without FPG respectively), added to lysis and treated with FPG enzyme to enhance sensitivity towards induced DNA lesions. After DNA unwinding and gel electrophoresis, slides were neutralized, stained with ethidium bromide and analyzed by fluorescence microscope (Zeiss, Germany). Per slide $2 \times 50$ cells were scored, averaged and the DNA damage was calculated as tail intensity (TI\%: DNA in the comet tail in percent of total DNA) [9, 37, 39]. Results were expressed as percent of Md-treated control.

\subsection{Cytotoxicity (alamar blue assay)}

Metabolic activity results in the chemical reduction of resazurin (blue and nonfluorescent) to resorufin (pink and highly fluorescent) [30]. After extract incubation, cells were washed with PBS, treated with serum free medium $(500 \mu \mathrm{l})$ containing $10 \%$ resazurin solution and measured by a microplate reader (MWG, Ebersberg, Germany) (excitation wavelength $530 \mathrm{~nm}$, emission wavelength $590 \mathrm{~nm}, 37^{\circ} \mathrm{C}$ ). Treatment with $0.1 \%$ saponin was used as positive control for cytotoxicity. Results were calculated as percent of control (without BE treatment).

\subsection{Statistics}

Results of the performed assays are presented as mean \pm SD of 3 to 6 independent experiments. Differences $(p<0.05)$ were determined by independent one-sided $t$-test by origin analysis $6.0\left(\right.$ Microcal $^{\mathrm{TM}} \mathrm{Origin}^{\circledR}$, Northampton, USA).

\section{Results and discussion}

\subsection{Cytotoxity}

Resorufin formation from resazurin (alamar blue assay) was analysed as a measure of cytotoxicity in terms of mitochondrial integrity and cell growth [30]. Incubation time of $1 \mathrm{~h}$ was used to minimize confounding factors like instability and degradation of the anthocyanins as reported earlier [20, 44]. As a positive control resorufin formation was completely inhibited $(0.1 \%$ saponin $)$, whereas under all other treatment conditions resorufin formation reached median $95 \%$ of the negative control. Only in HT-29 cells a significant effect at the highest concentration of $500 \mu \mathrm{g} / \mathrm{ml}$ BE (Fig. 2) was detectable. Our data are in good agreement with a study by Yi et al., who reported that higher doses from 1 to $3 \mathrm{mg} / \mathrm{ml}$ crude blueberry extract inhibited cell growth in HT-29 and Caco-2 cells [47], while other studies investigating cytotoxicity of corresponding anthocyanidins (aglycons) at longer incubation times, cell growth was inhibited also at lower concentrations [16, 20, 24].

\subsection{Intracellular ROS level}

The TBH induced modulation of the intracellular ROS level in HT-29 and Caco-2 cells after BE incubation (1 and $24 \mathrm{~h}$ ) was measured by DCF assay. Quercetin $(30 \mu \mathrm{M})$, used as a positive control, reduced cellular ROS level in the range of $20 \%$ as compared to the control as also demonstrated earlier [35]. With the $\mathrm{BE}$ (1 to $250 \mu \mathrm{g} / \mathrm{ml})$ a significant, concentration dependent decrease of intracellular ROS was observed at $50 \mu \mathrm{g} / \mathrm{ml}$ in Caco-2 and $250 \mu \mathrm{g} / \mathrm{ml}$ in HT-29 cells after 1 and $24 \mathrm{~h}$ incubation. Maximum reduction of ROS level in Caco-2 cells was detected at concentrations $>100 \mu \mathrm{g} / \mathrm{ml}$. The BE was less efficient in HT-29 cells, a significant reduction of ROS level was observed beginning at $250 \mu \mathrm{g} / \mathrm{ml}(24 \mathrm{~h}$ ), respectively (Fig. 3). Our results are comparable to a study of Milbury et al. [28], demonstrating significant decreases of intracellular ROS level in ARPE-19 cells after bilberry extract treatment $(0.01 \mu \mathrm{g} / \mathrm{ml})$. With a fermented apple extract a significant decrease of ROS level was observed only at higher concentration ranges [4]. 


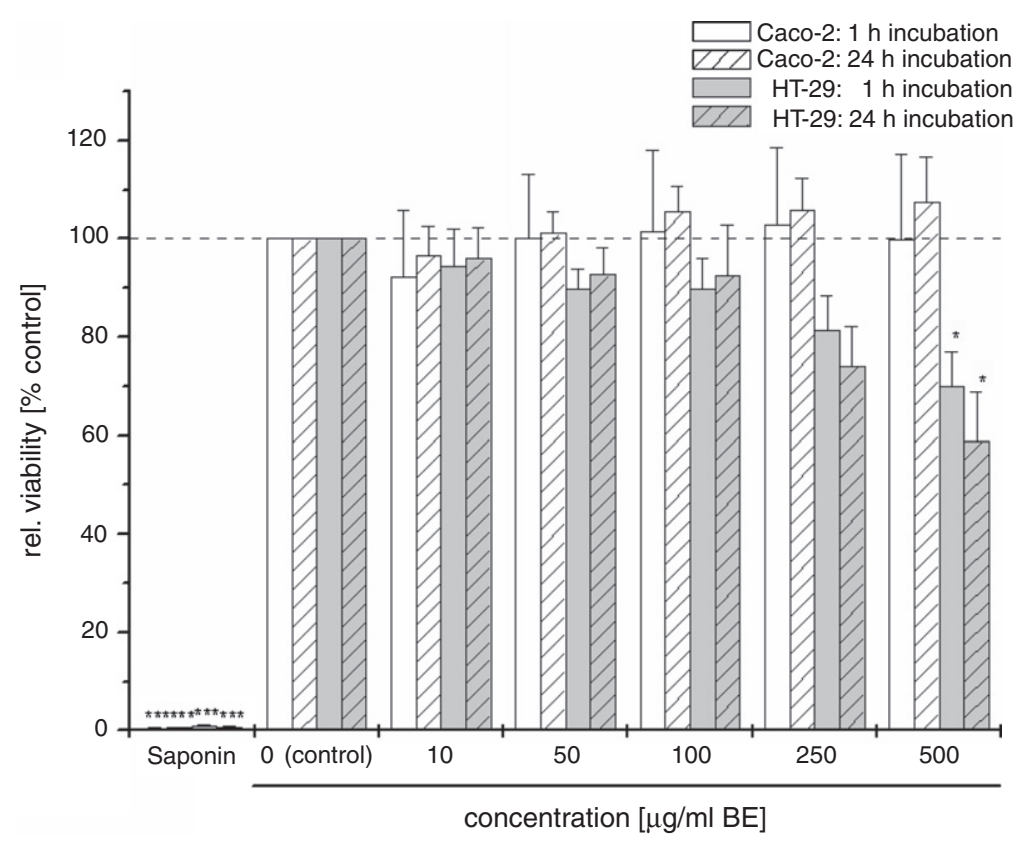

Fig. 2. Alamar blue assay to assess the cytotoxicity of an anthocyanin rich bilberry extract (BE) toward Caco-2 and HT-29 cells. For incubation, cells were treated with 10 to $500 \mu \mathrm{g} / \mathrm{ml} \mathrm{BE}$ for 1 and $24 \mathrm{~h}$ and incubated with resazurin for another $1 \mathrm{~h}$ whereby the fluorescence of resorufin was measured. Saponin was used as positive control for cytotoxicity. Results were calculated as percent of DMSO treated control; $n=4$ (mean \pm SD). Differences were determined by independent one-sided $t$-test related to the DMSO treated control: ${ }^{*} p<0.05, * * *<0.001$.

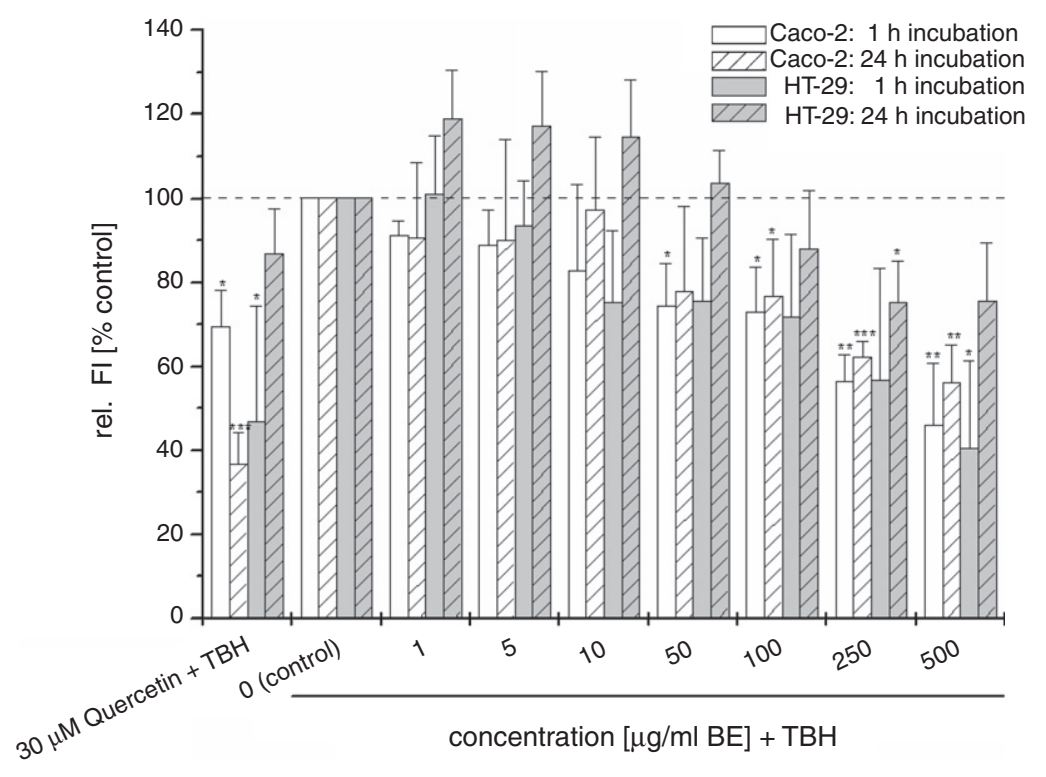

Fig. 3. Modulation of tert-butyl hydroperoxide (TBH)-induced intracellular ROS level in Caco-2 and HT-29 cells after 1 and $24 \mathrm{~h}$ incubation with an anthocyanin rich bilberry extract (BE) $(1$ to $500 \mu \mathrm{g} / \mathrm{ml})$. Results were calculated as percent of TBH treated control; $n=3-5$ (mean $\pm \mathrm{SD}$ ). Differences were determined by independent one-sided $t$-test related to the TBH treated control: $* p<0.05, * * p<0.01, * * * p<0.001$. 


\subsection{Oxidative DNA damage}

The comet assay was used to study the effects of the BE on the reduction of Md induced oxidative DNA damage in Caco-2 and HT-29 cells with and without FPG to enhance sensitivity towards ROS induced DNA lesions. Preventive effects of quercetin (positive control, $30 \mu \mathrm{M}$ ) reducing DNA damage in the range of $60 \%$ tail intensity (TI) compared to the control was demonstrated earlier in the literature [35]. After treatment of cells only with DMSO, a basal level of 24 to $31 \%$ TI was measured in Caco-2 cells. A slight decrease of DNA damage was obtained in a range from 5 to $100 \mu \mathrm{g} / \mathrm{ml}$ BE in Caco-2 cells. Concentration curves, resembling a "U-shape", were observed reaching a minimum at $5 \mu \mathrm{g} / \mathrm{ml}$. Significant DNA-protecting effects were shown after $24 \mathrm{~h}$ of incubation with $50 \mu \mathrm{g} / \mathrm{ml} \mathrm{BE}$ and $5 \mu \mathrm{g} / \mathrm{ml}$ BE treated with FPG, respectively (Fig. 4). No reduction of Md induced DNA damages in HT-29 cells was observed (data not shown). The "U-shaped" form of concentration curve in the same test system was also observed earlier with apple juice extract [35]. In low BE $(0.01$ to $1 \mu \mathrm{g} / \mathrm{ml})$ concentrations no effects and in high BE concentrations ( 250 to $500 \mu \mathrm{g} / \mathrm{ml}$ ) a prooxidative effect was detectable. These data are also in agreement with the results of an intervention study with hemodialysis patients consuming daily $200 \mathrm{ml}$ anthocyanin rich fruit juice, resulting in a significant decrease of oxidative DNA damage and a significant increase of GSH level in blood [38]. In another in vivo study with healthy volunteers who consumed an anthocyanin/polyphenolic-rich fruit juice, a decrease of oxidative DNA damage during the juice-uptake phase was observed [43].

\subsection{Cellular tGSH level}

In a photometric kinetic assay, the cellular tGSH level in Caco-2 and HT-29 cells after BE and Md treatment was measured. DMSO without further treatment as negative control, to quantify the basal level of tGSH in the cells, was used as a positive control, demonstrated tGSH levels in the range of $160 \%$ as compared to negative Md-control as published earlier [35]. After $24 \mathrm{~h}$ incubation, Caco-2 cells showed slight but insignificant tGSH increases in the highest used BE concentrations $(50-500 \mu \mathrm{g} / \mathrm{ml})$. In contrast, after $1 \mathrm{~h}$ incubation $500 \mu \mathrm{g} / \mathrm{ml}$ extract significantly reduced the

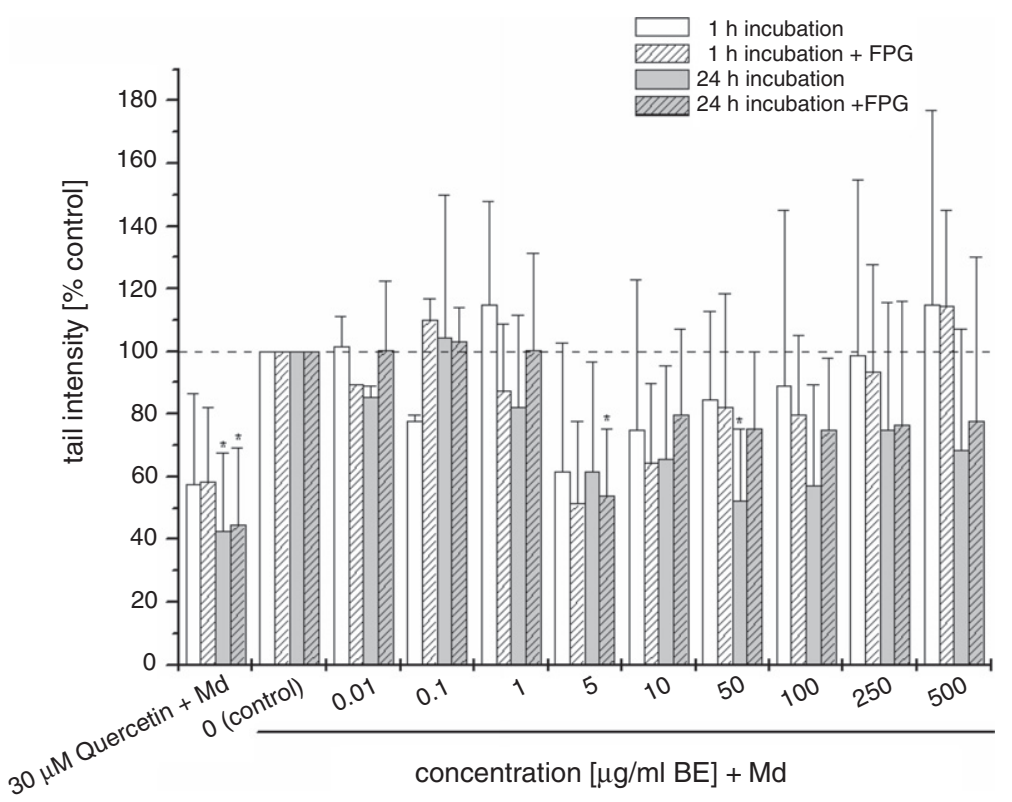

Fig. 4. Modulation of Menadione (Md)-induced (HT-29: $20 \mu \mathrm{M}$; Caco-2: $6 \mu \mathrm{M}$; $1 \mathrm{~h}$ ) oxidative DNA damage in Caco-2 cells after 1 and $24 \mathrm{~h}$ incubation with an anthocyanin rich bilberry extract (BE) $(0.01$ to $500 \mu \mathrm{g} / \mathrm{ml})$; quercetin $(30 \mu \mathrm{M})$ was used as positive control. Results were calculated as percent of Md treated control; $n=3-6$ (mean $\pm \mathrm{SD}$ ). Differences were determined by independent one-sided $t$-test related to the TBH treated control: $* p<0.05, * * * p<0.001$. 


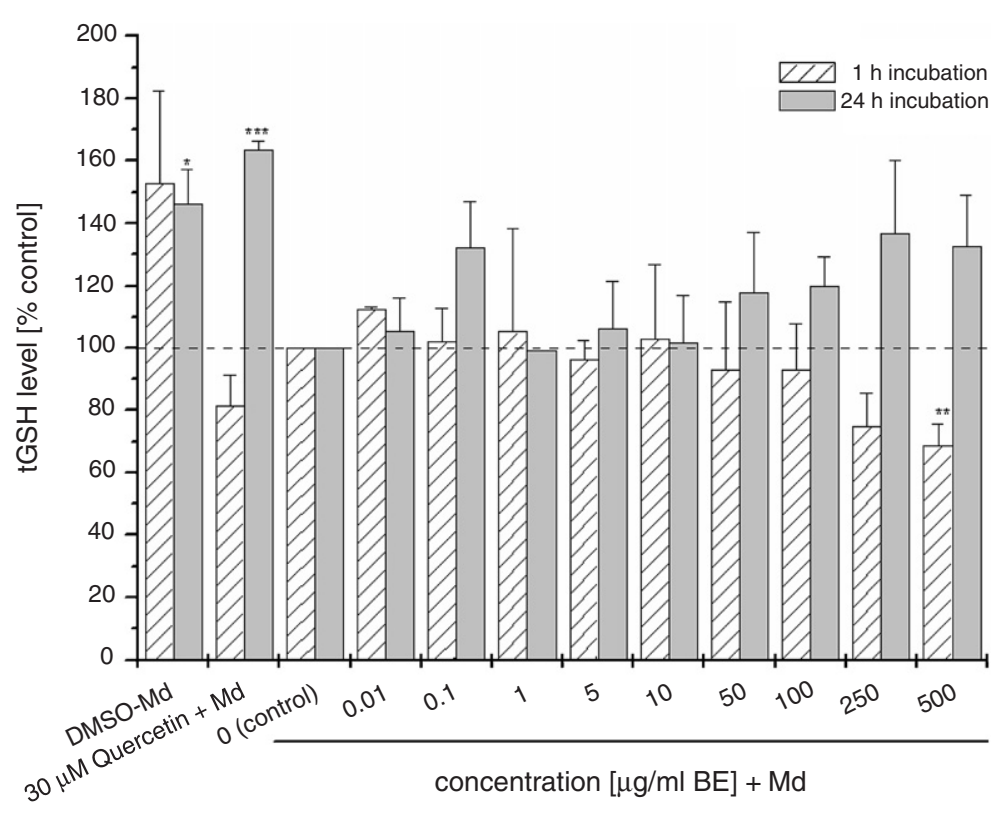

Fig. 5. Modulation of Md-induced total glutathione (tGSH) level in Caco-2 cells after 1 and $24 \mathrm{~h}$ incubation with an anthocyanin rich bilberry extract (BE) $(0.01$ to $500 \mu \mathrm{g} / \mathrm{ml})$; quercetin $(30 \mu \mathrm{M})$ was used as positive control. Results were calculated as percent of Md treated control; $n=3-6$ $($ mean $\pm \mathrm{SD})$. Differences were determined by independent one-sided $t$-test related to the TBH treated control: ${ }^{*} p<0.05$, ** $p<0.01$, *** $p<0.001$.

tGSH level down to about $70 \%$ of the negative control. BE in a range between 0.01 to $10 \mu \mathrm{g} / \mathrm{ml}$ induced no effects after 1 and $24 \mathrm{~h}$ of incubation in comparison to the negative control (Fig. 5). This suggests that low anthocyanin concentrations used have no effect on the tGSH level in the used cell systems. In contrast to our in vitro data, in vivo studies, one with hemodialysis patients and the other with healthy volunteers which consumed an anthocyanin/polyphenolic-rich fruit juice, an increased level of tGSH in blood after juice uptake was detectable [38, 43].

Taken together, our data indicate that anthocyanins from berries (bilberries) exert antioxidant activity contributing to the health preventing properties of fruits and vegetables. The anthocyanin profile of the used BE corresponds to those of native bilberries. Anthocyanin content of $1 \mathrm{~g}$ of enriched BE is equivalent to $17 \mathrm{~g}$ of native bilberries [23]. In a study with ileostomy volunteers who consumed $300 \mathrm{~g}$ blueberries (with a total anthocyanin amount of $7834 \mathrm{mg} / \mathrm{kg}$ ) up to $85 \%$ of the anthocyanins reached the colon [18]. He et al. quantified the anthocyanin uptake by small intestine tissue to be $7.5 \%$ of the administrated dose after $120 \mathrm{~min}$ in rats [15]. Due to these data concentrations in a range of 0.01 to $500 \mu \mathrm{g} / \mathrm{ml} \mathrm{BE}$ were investigated in our cellular systems.

As found by us, ROS level increases in Caco- 2 cells significantly at $50 \mu \mathrm{g} / \mathrm{ml} \mathrm{BE}$. These data are comparable to a study in which anthocyanins showed significant positive effects on intracellular ROS and lipid peroxidation in rat pheochromocytoma cells (PC-12) after incubation with sweet potato anthocyanins $(50 \mu \mathrm{g} / \mathrm{ml})$ [46]. Further in vitro studies with anthocyanins demonstrated the high antioxidative capacity due to their ability to scavenge free radicals $[17,21,40]$. Due to these scavenging effects, anthocyanins (2.5 $\mathrm{nm}$ in media) were able to stabilize the DNA against hydroperoxide radicals, associated with a decrease in DNA damage [25]. Acquaviva et al. monitored a concentration dependent (100 to $500 \mu \mathrm{mol} / \mathrm{l}$ ) reduction of plasmid DNA damage after cyanidin and cyanidin 3-Oglucoside treatment [1]. In agreement with these data our comet assay results showed significant DNA-protecting effects at 5 and $50 \mu \mathrm{g} / \mathrm{ml} \mathrm{BE}$ in Caco-2 cells. In two in vivo studies with mice under oxidative stress, positive effects of anthocyanin rich extracts (concentration range 100 to $200 \mathrm{mg} / \mathrm{kg} \mathrm{KG}$ ) like increasing tGSH level and other oxidative stress markers were reported [2, 32].

In total, we suppose that the preventive properties of the anthocyanin rich bilberry extract to reduce oxidative DNA damage, lower ROS level and elevate tGSH in human colon tumor cell lines, is associated with protection of the colon from oxidative stress. 


\section{Acknowledgements}

The authors gratefully acknowledge the gift of FPG enzyme by Prof. A.R. Collins (Institute for Nutrition Research, University of Oslo, Norway) and the Symrise GmbH \& Co.KG for BE characterization. This work was supported by Bundesministerium für Wirtschaft und Technologie/AiF via the Forschungskreis der Ernährungsindustrie e.V. (FEI), Bonn, project No. $15614 \mathrm{~N}$ for financial support.

\section{References}

[1] R. Acquaviva, A. Russo, F. Galvano, G. Galvano, M.L. Barcellona, G. Li Volti and A. Vanella, Cyanidin and cyanidin 3-O-beta-D-glucoside as DNA cleavage protectors and antioxidants, Cell Biology and Toxicology 19 (2003), 243-252.

[2] L. Bao, X.S. Yao, C.C. Yau, D. Tsi, C.S. Chia, H. Nagai and H. Kurihara, Protective effects of bilberry (Vaccinium myrtillus L.) extract on restraint stress-induced liver damage in mice, Journal of Agricultural and Food Chemistry 56 (2008), 7803-7807.

[3] M. Battino, J. Beekwilder, B. Denoyes-Rothan, M. Laimer, G.J. McDougall and B. Mezzetti, Bioactive compounds in berries relevant to human health, Nutrition Reviews 67 (2009), S145-S150.

[4] P. Bellion, T. Hofmann, B.L. Pool-Zobel, F. Will, H. Dietrich, B. Knaup, E. Richling, M. Baum, G. Eisenbrand and C. Janzowski, Antioxidant effectiveness of phenolic apple juice extracts and their gut fermentation products in the human colon carcinoma cell line caco-2, Journal of Agricultural and Food Chemistry 56 (2008), 6310-6317.

[5] P. Bellion, M. Olk, F. Will, H. Dietrich, M. Baum, G. Eisenbrand and C. Janzowski, Formation of hydrogen peroxide in cell culture media by apple polyphenols and its effect on antioxidant biomarkers in the colon cell line HT-29, Molecular Nutrition \& Food Research 53 (2009), 1226-1236.

[6] G. Bobe, B. Wang, N.P. Seeram, M.G. Nair and L.D. Bourquin, Dietary anthocyanin-rich tart cherry extract inhibits intestinal tumorigenesis in APC(Min) mice fed suboptimal levels of sulindac, Journal of Agricultural and Food Chemistry 54 (2006), 9322-9328.

[7] L. Chalker-Scott, Environmental significance of anthocyanins in plant stress responses, Photochemistry and Photobiology 70 (1999), 1-9.

[8] M.N. Clifford, Anthocyanins - nature, occurrence and dietary burden, Journal of the Science of Food and Agriculture 80 (2000), $1063-1072$.

[9] A.R. Collins, A.A. Oscoz, G. Brunborg, I. Gaivao, L. Giovannelli, M. Kruszewski, C.C. Smith and R. Stetina, The comet assay: topical issues, Mutagenesis 23 (2008), 143-151.

[10] D. Cooke, M. Schwarz, D. Boocock, P. Winterhalter, W.P. Steward, A.J. Gescher and T.H. Marczylo, Effect of cyanidin-3-glucoside and an anthocyanin mixture from bilberry on adenoma development in the Apc(Min) mouse model of intestinal carcinogenesis-Relationship with tissue anthocyanin levels, International Journal of Cancer 119 (2006), 2213-2220.

[11] J.M. Cooney, D.J. Jensen and T.K. McGhie, LC-MS identification of anthocyanins in boysenberry extract and anthocyanin metabolites in human urine following dosing, Journal of the Science of Food and Agriculture 84 (2004), 237-245.

[12] S. de Pascual-Teresa and M.S. Sanchez-Ballesta, Anthocyanins: from plant to health, Phytochemistry Reviews (2008), 281-299.

[13] D. Fridrich, M. Kern, G. Pahlke, N. Volz, F. Will, H. Dietrich and D. Marko, Apple polyphenols diminish the phosphorylation of the epidermal growth factor receptor in HT29 colon carcinoma cells, Molecular Nutrition \& Food Research 51 (2007), 594-601.

[14] B.B. Hafeez, I.A. Siddiqui, M. Asim, A. Malik, F. Afaq, V.M. Adhami, M. Saleem, M. Din and H. Mukhtar, A dietary anthocyanidin delphinidin induces apoptosis of human prostate cancer PC3 cells in vitro and in vivo: involvement of nuclear factor-kappaB signaling, Cancer Research 68 (2008), 8564-8572.

[15] J. He, T.C. Wallace, K.E. Keatley, M.L. Failla and M.M. Giusti, Stability of black raspberry anthocyanins in the digestive tract lumen and transport efficiency into gastric and small intestinal tissues in the rat, Journal of Agricultural and Food Chemistry 57 (2009), 3141-3148.

[16] P. Jing, J.A. Bomser, S.J. Schwartzt, J. He, B.A. Magnuson and M.M. Giusti, Structure-function relationships of anthocyanins from various anthocyanin-rich extracts on the inhibition of colon cancer cell growth, Journal of Agricultural and Food Chemistry 56 (2008), 9391-9398.

[17] M.P. Kahkonen and M. Heinonen, Antioxidant activity of anthocyanins and their aglycons, Journal of Agricultural and Food Chemistry 51 (2003), 628-633.

[18] K. Kahle, M. Kraus, W. Scheppach, M. Ackermann, F. Ridder and E. Richling, Studies on apple and blueberry fruit constituents: Do the polyphenols reach the colon after ingestion?, Molecular Nutrition \& Food Research 50 (2006), 418-423.

[19] N. Katsube, K. Iwashita, T. Tsushida, K. Yamaki and M. Kobori, Induction of apoptosis in cancer cells by Bilberry (Vaccinium myrtillus) and the anthocyanins, Journal of Agricultural and Food Chemistry 51 (2003), 68-75.

[20] M. Kern, D. Fridrich, J. Reichert, S. Skrbek, A. Nussher, S. Hofem, S. Vatter, G. Pahlke, C. Rufer and D. Marko, Limited stability in cell culture medium and hydrogen peroxide formation affect the growth inhibitory properties of delphinidin and its degradation product gallic acid, Molecular Nutrition \& Food Research 51 (2007), 1163-1172.

[21] T. Kulisic-Bilusic, K. Schnabele, I. Schmoller, V. Dragovic-Uzelac, A. Krisko, B. Dejanovic, M. Milos and G. Pifat, Antioxidant activity versus cytotoxic and nuclear factor kappa B regulatory activities on HT-29 cells by natural fruit juices, European Food Research and Technology 228 (2009), 417-424. 
[22] T. Lapidot, M.D. Walker and J. Kanner, Can apple antioxidants inhibit tumor cell proliferation? Generation of H2O2 during interaction of phenolic compounds with cell culture media, Journal of Agricultural and Food Chemistry 50 (2002), 3156-3160.

[23] A.K. Latti, K.R. Riihinen and P.S. Kainulainen, Analysis of anthocyanin variation in wild populations of bilberry (Vaccinium myrtillus L.) in Finland, Journal of Agricultural and Food Chemistry 56 (2008), 190-196.

[24] D. Marko, N. Puppel, Z. Tjaden, S. Jakobs and G. Pahlke, The substitution pattern of anthocyanidins affects different cellular signaling cascades regulating cell proliferation, Molecular Nutrition \& Food Research 48 (2004), 318-325.

[25] T. Mas, J. Susperregui, B. Berke, C. Cheze, S. Moreau, A. Nuhrich and J. Vercauteren, DNA triplex stabilization property of natural anthocyanins, Phytochemistry 53 (2000), 679-687.

[26] T.K. McGhie and M.C. Walton, The bioavailability and absorption of anthocyanins: Towards a better understanding, Molecular Nutrition \& Food Research 51 (2007), 702-713.

[27] H.M. Merken and G.R. Beecher, Measurement of food flavonoids by high-performance liquid chromatography: A review, Journal of Agricultural and Food Chemistry 48 (2000), 577-599.

[28] P.E. Milbury, B. Graf, J.M. Curran-Celentano and J.B. Blumberg, Bilberry (Vaccinium myrtillus) anthocyanins modulate heme oxygenase-1 and glutathione S-transferase-pi expression in ARPE-19 cells, Investigative Ophthalmology \& Visual Science 48 (2007), $2343-2349$.

[29] N.A. Nyman and J.T. Kumpulainen, Determination of anthocyanidins in berries and red wine by high-performance liquid chromatography, Journal of Agricultural and Food Chemistry 49 (2001), 4183-4187.

[30] J. O'Brien, I. Wilson, T. Orton and F. Pognan, Investigation of the alamar blue (resazurin) fluorescent dye for the assessment of mammalian cell cytotoxicity, European Journal of Biochemistry 267 (2000), 5421-5426.

[31] M.E. Olsson, K.E. Gustavsson, S. Andersson, A. Nilsson and R.D. Duan, Inhibition of cancer cell proliferation in vitro by fruit and berry extracts and correlations with antioxidant levels, Journal of Agricultural and Food Chemistry 52 (2004), 7264-7271.

[32] M.M. Rahman, T. Ichiyanagi, T. Komiyama, S. Sato and T. Konishi, Effects of anthocyanins on psychological stress-induced oxidative stress and neurotransmitter status, Journal of Agricultural and Food Chemistry 56 (2008), 7545-7550.

[33] A. Scalbert, C. Manach, C. Morand, C. Remesy and L. Jimenez, Dietary polyphenols and the prevention of diseases, Critical Reviews in Food Science and Nutrition 45 (2005), 287-306.

[34] J. Scalzo, A. Currie, J. Stephens, T. McGhie, P. Alspach and H.F.R.I.N. Zea, The anthocyanin composition of different Vaccinium, Ribes and Rubus genotypes, Biofactors 34 (2008), 13-21.

[35] S. Schaefer, M. Baum, G. Eisenbrand, H. Dietrich, F. Will and C. Janzowski, Polyphenolic apple juice extracts and their major constituents reduce oxidative damage in human colon cell lines, Molecular Nutrition \& Food Research 50 (2006), 24-33.

[36] N.J. Simmonds and D.S. Rampton, Inflammatory bowel-disease-a radical view, Gut 34 (1993), 865-868.

[37] N.P. Singh, M.T. Mccoy, R.R. Tice and E.L. Schneider, A simple technique for quantitation of low-levels of DNA damage in individual cells, Experimental Cell Research 175 (1988), 184-191.

[38] T.M. Spormann, F.W. Albert, T. Rath, H. Dietrich, F. Will, J.P. Stockis, G. Eisenbrand and C. Janzowski, Anthocyanin/polyphenolic-rich fruit juice reduces oxidative cell damage in an intervention study with patients on hemodialysis, Cancer Epidemiology, Biomarkers \& Prevention 17 (2008), 3372-3380.

[39] R.R. Tice, E. Agurell, D. Anderson, B. Burlinson, A. Hartmann, H. Kobayashi, Y. Miyamae, E. Rojas, J.C. Ryu and Y.F. Sasaki, Single cell gel/comet assay: Guidelines for in vitro and in vivo genetic toxicology testing, Environmental and Molecular Mutagenesis 35 (2000), 206-221.

[40] T. Tsuda, F. Horio, K. Uchida, H. Aoki and T. Osawa, Dietary cyanidin 3-O-beta-D-glucoside-rich purple corn color prevents obesity and ameliorates hyperglycemia in mice, Journal of Nutrition 133 (2003), 2125-2130.

[41] H. Wang, G.H. Cao and R.L. Prior, Oxygen radical absorbing capacity of anthocyanins, Journal of Agricultural and Food Chemistry 45 (1997), 304-309.

[42] H. Wang and J.A. Joseph, Quantifying cellular oxidative stress by dichlorofluorescein assay using microplate reader, Free Radical Biology and Medicine 27 (1999), 612-616.

[43] T. Weisel, M. Baum, G. Eisenbrand, H. Dietrich, F. Will, J.P. Stockis, S. Kulling, C. Rufer, C. Johannes and C. Janzowski, An anthocyanin/polyphenolic-rich fruit juice reduces oxidative DNA damage and increases glutathione level in healthy probands, Biotechnology Journal 1 (2006), 388-397.

[44] G. Woodward, P. Kroon, A. Cassidy and C. Kay, Anthocyanin stability and recovery: Implications for the analysis of clinical and experimental samples, Journal of Agricultural and Food Chemistry 57 (2009), 5271-5278.

[45] X.L. Wu, G.R. Beecher, J.M. Holden, D.B. Haytowitz, S.E. Gebhardt and R.L. Prior, Concentrations of anthocyanins in common foods in the United States and estimation of normal consumption, Journal of Agricultural and Food Chemistry 54 (2006), 4069-4075.

[46] J. Ye, X. Meng, C. Yan and C. Wang, Effect of purple sweet potato anthocyanins on beta-amyloid-mediated PC-12 cells death by inhibition of oxidative stress, Neurochemical Research 35 (2009), 357-365.

[47] W.G. Yi, J. Fischer, G. Krewer and C.C. Akoh, Phenolic compounds from blueberries can inhibit colon cancer cell proliferation and induce apoptosis, Journal of Agricultural and Food Chemistry 53 (2005), 7320-7329.

[48] Z. Zhang, X.L. Kou, K. Fugal and J. McLaughlin, Comparison of HPLC methods for determination of anthocyanins and anthocyanidins in bilberry extracts, Journal of Agricultural and Food Chemistry 52 (2004), 688-691. 